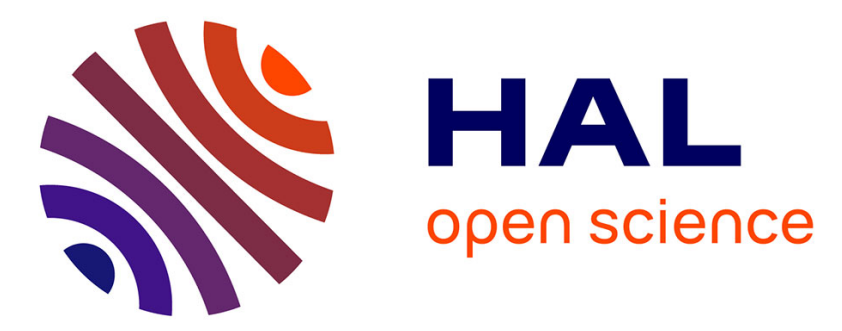

\title{
Reversible Morphological Control of Cholecystokinin Tetrapeptide Amyloid Assemblies as a Function of pH
} Frédéric Gobeaux, Florence Porcher, Rajeev Dattani

\section{To cite this version:}

Frédéric Gobeaux, Florence Porcher, Rajeev Dattani. Reversible Morphological Control of Cholecystokinin Tetrapeptide Amyloid Assemblies as a Function of pH. Journal of Physical Chemistry B, 2017, 121 (14), pp.3059 - 3069. 10.1021/acs.jpcb.7b02448 . cea-01510377

\section{HAL Id: cea-01510377 https://hal-cea.archives-ouvertes.fr/cea-01510377}

Submitted on 19 Apr 2017

HAL is a multi-disciplinary open access archive for the deposit and dissemination of scientific research documents, whether they are published or not. The documents may come from teaching and research institutions in France or abroad, or from public or private research centers.
L'archive ouverte pluridisciplinaire HAL, est destinée au dépôt et à la diffusion de documents scientifiques de niveau recherche, publiés ou non, émanant des établissements d'enseignement et de recherche français ou étrangers, des laboratoires publics ou privés.

\section{(c)(1)}

Distributed under a Creative Commons Attribution| 4.0 International License 


\title{
Reversible Morphological Control of Cholecystokinin Tetrapeptide Amyloid Assemblies as a Function of $\mathrm{pH}$
}

\author{
Frédéric Gobeaux, ${ }^{\mathrm{a}, *}$ Florence Porcher ${ }^{\mathrm{b}}$ and Rajeev Dattani ${ }^{\mathrm{c}}$ \\ ${ }^{a}$ LIONS - NIMBE CEA, CNRS, Université Paris-Saclay, CEA Saclay, 91191 Gif-sur-Yvette Cedex, France \\ baboratoire Léon Brillouin, CEA Saclay, 91191 Gif-sur-Yvette, France \\ ${ }^{\mathrm{c}}$ ESRF - The European Synchrotron, 71 avenue des Martyrs, 38000 Grenoble, France
}

\begin{abstract}
Most amyloid assemblies are seen as irreversible and exhibit polymorphism because their assembly is kinetically controlled and different structures are trapped during the aggregation process. However, in the specific case of peptide hormones, formation of amyloid assemblies for storage purposes has been reported. This suggests a strict control of assembly and the ability to disassemble upon hormone secretion. In the present work, we have sought to test these assertions with a short peptide, the cholecystokinin (or gastrin) tetrapeptide (CCK-4), that has been found in both gastrointestinal tract and central nervous system, and whose sequence is shared by a large number of hormones. We have thus studied in vitro this peptide's self-assembling properties in dense phases at different $\mathrm{pH}$ levels, thus mimicking in vivo storage conditions. The solubility and morphology of the supramolecular assemblies have been shown to vary with the $\mathrm{pH}$. At low $\mathrm{pH}$, the tetrapeptide exhibits a low solubility and forms microcrystals. At higher $\mathrm{pH}$ levels, peptide solubility increases and above a high enough concentration, peptide monomers self-assemble into typical amyloid fibrils of 10-20 nm diameter. The physical network formed by these fibrils results in a birefringent hydrogel phase. Despite the different morphological features exhibited at different $\mathrm{pH}$, structural analysis shows strong similarities. Both supramolecular assemblies - microcrystals and fibrils - are structured by $\beta$-sheets. We also show that all these morphologies are reversible and can be either dissolved or changed into one another by switching the $\mathrm{pH}$. In addition, we demonstrate that a modification in the charge sequence of the peptide by amino acid mutation modifies its self-assembly properties. In conclusion, just as the CCK-4 sequence is the minimal sequence required for a complete biological activity at $\mathrm{CCK}_{\mathrm{B}}$ receptors in the brain, it is also sufficient to form amyloid fibers whose properties can be related to hormone storage and release purposes in vivo.
\end{abstract}




\section{INTRODUCTION}

Until recently, the study of amyloid fibril assembly and structure has mainly been motivated by the will to understand the formation of pathological aggregations as observed in neurodegenerative diseases such as Alzheimer's, Parkinson's or Huntington's. The fibril formation proceeds from the misfolding of small proteins (or large peptides) which are usually constituted from a few tens up to a few hundreds of amino-acids. ${ }^{1}$ The most studied models are amyloid- $\beta$ protein ${ }^{2}$, amylin or $\alpha$-synuclein. ${ }^{3}$ Nevertheless, numerous examples were found in which proteins or peptides are assembled into amyloid-like fibrils that fulfill a beneficial role such as cytoprotection ${ }^{4,5,6}$, cell adhesion ${ }^{7}$ or regulation of melanin biosynthesis. ${ }^{8}$ As a consequence, these systems were named "functional amyloids". 9 Moreover, these types of amyloid fibrils seem to be ubiquitous in the biological realm since they can be found in plants ${ }^{10}$, fungi ${ }^{11}$ and bacteria ${ }^{12,13}$ as well as in mammals. ${ }^{7,8,14,15}$ All these examples highlight the potential of amyloids in the development of novel functional biomaterials. In contrast with pathological amyloids, functional amyloids are formed by amino acid sequences that have been selected during evolution. Hence we can expect that they follow robust assembly processes, have well-defined structures and that they are harmless. Additionally, they don't require destabilizing conditions (organic solvents or alcohol, extreme $\mathrm{pH}$ conditions etc...) to selfassemble, which makes them biocompatible.

Many of these functional amyloids result from the assembly of small proteins (most of them count well over 100 amino acids) that are difficult to purify and present complex co-aggregation phenomena, which render in vitro studies tedious. Thus, there is a strong incentive to study shorter peptides stemming from functional amyloid systems. By studying the family of pituitary peptide hormones, which were slightly shorter (9-41 amino acids, with an outlier at 199), Maji et al. opened new avenues. ${ }^{16}$ Likewise, studies on peptide hormone analogues conducted by Paternostre \& Artzner et al. have demonstrated the biophysical insight that can be retrieved from the study of this class of peptides. ${ }^{17-20}$ Indeed, using a short peptide sequence makes it easier to identify the molecular determinants driving the assembly and controlling the supramolecular structures. The specific role of side chains and charges can be finely addressed and potential molecular dynamic simulation tractable. Moreover, the storage functionality of hormones amyloids suggests that their assembly is reversible upon well-defined triggers. Finally, peptide hormones self-assembly properties can be harnessed for therapeutic applications. ${ }^{21}$

In the frame of the present study we have assessed the selfassembly properties of the cholecystokinin tetrapeptide (CCK-4) also known as gastrin tetrapeptide - as a function of $\mathrm{pH}$. This sequence corresponds to the last four amino acids of the gastrin and the cholecystokinin C-terminus peptides that are respectively synthesized in the intestine and in the brain. In both cases it corresponds to the minimal sequence required for complete biological activity at the G-protein coupled receptor $\mathrm{CCK}_{\mathrm{B}}$ in both the central nervous system and gastrointestinal tract. ${ }^{26}$ As such it is commonly used in experimental pharmacology to investigate the biological effects mediated by this receptor. ${ }^{27}$ CCK-4 has been found in nerve terminals in pancreatic islets and reported to act as a potent releaser of insulin and other islet hormones. ${ }^{28}$ There is also evidence suggesting that CCK-4 - along with CCK-33 and CCK-8 - acts as a neurotransmitter or neuromodulator in the central nervous system. ${ }^{29-31}$ Indeed, CCK-related peptides are thought to participate in the central control of stress response and stress-induced memory dysfunctions. ${ }^{32}$ It is also worth mentioning that gastrin and cholecystokinin peptides have been found in dense secretory granules ${ }^{33,34}$. We can hypothesize that they are stored under an aggregated form - very likely amyloid structures, as other peptide hormones are. ${ }^{16}$

The amino acid sequence of the CCK-4 fragment is Trp-MetAsp-Phe- $\mathrm{NH}_{2}$. From now on it will be referred to as WMDF. Its detailed formula can be seen in Figure 1A. From a structural point of view, it is an amphiphilic peptide with two aromatic residues at the termini, respectively a tryptophan at the N-terminus and a phenylalanine at the $\mathrm{C}$-terminus. The $\mathrm{C}$-terminus is additionally amidified. In between, the two central residues are methionine, which can potentially be functionalized ${ }^{35,36}$, and aspartic acid, whose side-chain is negatively charged above $\mathrm{pH}$ 3.7. Another charge appears below $\mathrm{pH} 9.3$ by protonation of the N-terminal. The resulting net charge of the peptide thus varies between -1 and +1 passing through zero at $\mathrm{pH}$ 6.1 (See Figure 1B). Between 3.71 and 8.76 the peptide adopts a zwitterionic form. This suggests that the backbone conformation and solubility strongly depends on the $\mathrm{pH}$. To assess the role of the charge borne by the aspartic acid, we have also characterized the assembling properties of an analogue whose sequence Trp-Met-Asn-Phe- $\mathrm{NH}_{2}$ (referred to as WMNF in the following text) in which the aspartic acid residue is replaced by an asparagine residue whose side chain is polar and uncharged. The only remaining charge is thus the $\mathrm{N}$-terminus at acidic $\mathrm{pH}$. Above $\mathrm{pH}$ 10, WMNF bears no charge at all.
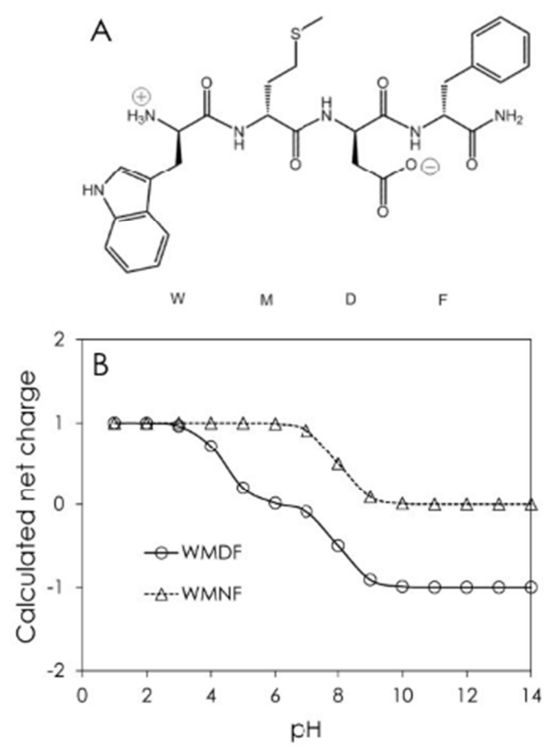

Figure 1: A) WMDF in its zwitterionic form (e.g. at zero net charge $\mathrm{pH} 6.2$ ). B) Calculated net charges for WMDF and WMNF sequences as a function of $\mathrm{pH}$.

We will first show that the ionic state of the peptide plays a significant role in the morphology of the supramolecular assemblies and study their structure and conformation by small angle Xray scattering (SAXS) and vibrational spectroscopies; the second section will establish the reversible nature of these structures. In a third section, we will further highlight the specific role of the charge borne by aspartic acid in studying the mutant peptide WMNF. Finally, we will discuss the biological relevance of the WMDF assembly diagram as a function of $\mathrm{pH}$ and concentration in term of hormone storage and release. 


\section{EXPERIMENTAL SECTION}

Peptides. The WMDF-NH $\mathrm{N}_{2}$ and $\mathrm{WMNF}-\mathrm{NH}_{2}$ peptides were purchased from Bachem (Switzerland). The WMDF-acetate and WMNF-TFA lyophilized salts were weighed and dissolved in the appropriate aqueous buffer at room temperature. The solutions were homogenized by vortexing.

Transmission electron microscopy. Transmission electron microscopy was performed on a Philips CM12 electron microscope operated at $80 \mathrm{kV}$. A drop of the solution at 3-5\% w/w was deposited on a copper grid covered with a carbon film (Agar Scientific). After blotting off of the excess liquid, the material was stained with a $2 \%$ uranyle acetate solution or a $1.5 \%$ ammonium molybdate solution.

X-ray scattering and $x$-ray diffraction. SAXS-WAXS experiments were performed at the European Synchrotron Facility (ESRF), on the ID02 beamline. The wavelength of the incident beam was $0.995 \AA$ with exposure times of the order of 0.1-0.5 s. The scattered X-ray were collected on two Rayonix 2D-detectors, covering respectively $q$-ranges of $0.0075-0.64 \AA^{-1}$ and $0.53-$ $4.33 \AA^{-1}$. The WAXS patterns reported in Figure 3D were obtained on an in-house set-up. The X-rays were produced by a Molybdene anode. The wavelength of the incident beam was of $0.722 \AA$. The scattered pattern was collected on a MAR detector. The sample-to-detector distance was $72 \mathrm{~cm}$. The samples were inserted in $1.5 \mathrm{~mm}$ diameter quartz capillaries sealed with paraffin wax or spread on a kapton cell (10\% WMDF in PBS and 5\% WMNF in $\mathrm{NaOH}$ ). The spectra were manipulated and analyzed using the SaxsUtilities (www.sztucki.de/SAXSutilities/) and SasView (http://www.sasview.org/) softwares. Attempts to index the diffraction patterns were made using the DICVOL06 program. ${ }^{37} \mathrm{~A}$ series of cells was proposed by the software from analysis of the 19 peaks common in the two diffractograms. We used the following criteria to select the most relevant cells: (i) Cells must be compatible with the dimensions of the peptide $\sim 9 \AA \mathrm{x}$ $\sim 20 \AA, V=1153 \AA^{3}$; (ii) All the peaks have to be indexed; (iii) Cells must not generate too many peaks that are not experimentally detected.

Attenuated Total Reflectance Fourier Transform Infrared (ATR-FTIR). ATR-FTIR spectra were recorded at a $2-\mathrm{cm}^{-1}$ resolution with a Bruker IFS 66 spectrophotometer equipped with a $45^{\circ} \mathrm{N}$ ZnSe ATR attachment. The spectra obtained resulted from the average of 30 scans and were corrected for the linear dependence on the wavelength of the absorption measured by ATR. The water signal was removed by subtraction of pure water spectrum multiplied by a coefficient chosen by superimposing the spectra in the $2500-4000 \mathrm{~cm}^{-1}$ region. Afterwards, the spectra were normalized by setting the highest peak of the amide I band to 1 . The spectra were then deconvoluted with PeakFit (Systat Software Inc) as a sum of Gaussian-Lorentzian components using the secondary derivative method. A linear baseline was used.

Fourier-Transform Raman Spectroscopy (FT-Raman). FTRaman spectra were recorded at a $4-\mathrm{cm}^{-1}$ resolution with a Bruker IFS 66 spectrophotometer. The scattered light from a HeNe laser $(\lambda=632 \mathrm{~nm})$ was emitted $(452 \mathrm{~mW}$ incident power) at the sample and was analyzed at a right angle. A nitrogen cooled CCD detector was used to collect Stokes Raman data. In order to check the possible degradation of the sample under the beam, we acquired series of 500 spectra. The plotted spectra are thus the average of $100 \times 500$ spectra, which correspond to an accumulated acquisition time of 20 hours. The samples were conditioned in quartz capillary tubes sealed with paraffin wax.
Steady-state Fluorescence. The influence of the $\mathrm{pH}$ on the fluorescence emission of the WMDF peptide was assessed by performing two titrations of two $1 \mathrm{mg} / \mathrm{ml} \mathrm{samples.} \mathrm{The} \mathrm{first} \mathrm{sam-}$ ple was prepared in $0.5 \mathrm{M}$ acetic acid and titrated with $1 \mathrm{M}$ $\mathrm{NaOH}$. The second sample was prepared in $0.2 \mathrm{M} \mathrm{NaOH}$ and titrated with $1 \mathrm{M} \mathrm{HCl}$. The solutions were excited by a wavelength at $286 \mathrm{~nm}$. Although some measurements were made with samples with absorbance values higher than 0.3 (as typically advised to avoid reabsorption effects by neighboring molecules), controls showed that the position of the peak maxima $\lambda_{\max }$ were not impacted by concentrations. Intensities are given in arbitrary units. This was in particular unavoidable in order to probe the effect of assembly on the fluorescence. ThT fluorescence assays have also been performed. These results are displayed and commented in details in the ESI section.

\section{RESULTS AND DISCUSSION}

\section{WMDF polymorphism as a function of $\mathrm{pH}$.}

WMDF is poorly soluble in acidic conditions (e.g. in acetic acid, between $\mathrm{pH} 2.4$ and 5) and at intrinsic $\mathrm{pH}$ (i.e., when dissolved in pure water, $\mathrm{pH} \sim 6$ ) at concentration as low as $0.1 \mathrm{~g} / \mathrm{L}$. One obtains large aggregates that sediment to the bottom of the Eppendorf tube while the supernatant remains liquid. The concentration of peptide in the supernatant is estimated to be $\sim 1.5 \mathrm{mM}$ via $\mathrm{UV}$ absorption spectroscopy. When the $\mathrm{pH}$ is increased above $\mathrm{pH}$ 7 , the solubility also increases. Macroscopically, the samples at concentrations below 5\% w/w are clear liquids. Above $5-7 \% \mathrm{w} / \mathrm{w}$, they form gels that are birefringent when observed between crosspolarizers (Figure 2A). At pH 7-8 (0.1 M PBS), however, the gels are whitish while at $\mathrm{pH} 13(0.2 \mathrm{M} \mathrm{NaOH})$ they are completely transparent. ThT fluorescence assays performed on liquid suspension $(\mathrm{pH} \mathrm{6)}$ and gel $(\mathrm{pH} 9)$ show an increase of fluorescence emission at $482 \mathrm{~nm}$ in both cases (See ESI, Figure S5), which is widely regarded as a diagnostic of amyloid formation.
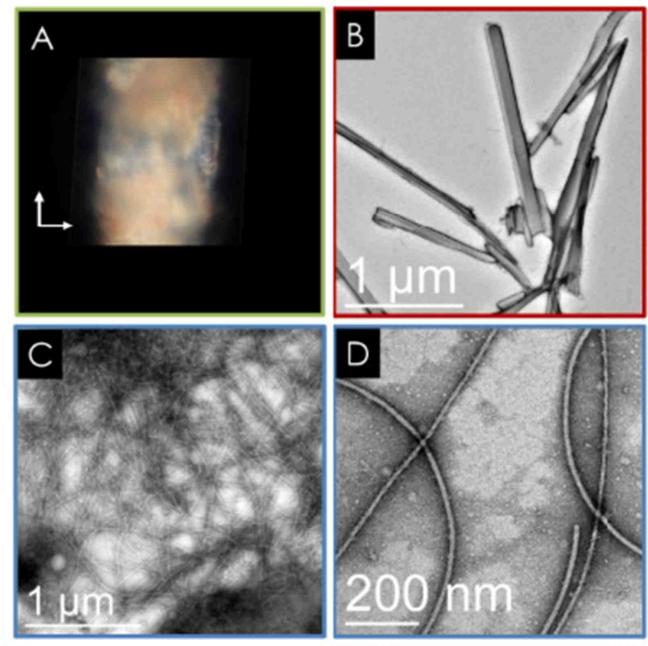

Figure 2: A) Polarized optical microscope picture of a $10 \% \mathrm{w} / \mathrm{w}$ gel of WMDF solubilized in a phosphate buffer $0.1 \mathrm{M}(\mathrm{pH} 7.4)$ inserted in a quartz capillary. B) Transmission electron micrograph of a solution of WMDF solubilized in $0.5 \mathrm{M}$ acetic acid ( $\mathrm{pH}$ 2.5). C-D) Transmission electron micrographs of a $5 \% \mathrm{w} / \mathrm{w}$ solution of WMDF solubilized in a 0.1 M phosphate buffer ( $\mathrm{pH}$ 7.4).

Transmission electron microscopy (TEM) gives access to the morphology of the objects formed in solution. In the suspensions of WMDF dissolved in acetic acid or water, straight and elongated 
crystals are observed (Figure 2B). Their length is of the order of the micron or more and their aspect ratio is about $1: 10$. In contrast, solutions prepared at higher $\mathrm{pH}$ appear to contain several micron-long unbranched fibrils, with an estimated diameter of $19 \pm 7 \mathrm{~nm}$, very similar to amyloid fibrils as they are classically described $^{38}$ (Figure 2C-D). At intermediate pH (e.g. 6-7), a coexistence between the microcrystal and fibril morphologies can be observed. The proportion of the two species seems to depend on the $\mathrm{pH}$ since at $\mathrm{pH} 6$ the crystals are predominant, while at higher $\mathrm{pH}$ fibrils take over. It is also noticeable that the crystals formed at higher $\mathrm{pH}$ seem less sharp than those formed at $\mathrm{pH}$ 2.5-5.

The structural features of the WMDF basic solutions are further probed by small angle X-ray scattering (SAXS). Figure 3A-B exhibit the $2 \mathrm{D}$-scattering patterns of a $10 \% \mathrm{w} / \mathrm{w}$ WMDF solution solubilized in $\mathrm{NH}_{4} \mathrm{Ac} 0.2 \mathrm{M}(\mathrm{pH}$ 11) collected the SAXS and WAXS detectors of the ID02 beamline, ESRF respectively. These oriented patterns clearly show the typical cross- $\beta$ pattern characteristic of amyloid fibers. Three main reflections are indicated by arrows labelled $m e r$ (for meridional), $e q$ (for equatorial) and $a$, at respectively $1.34 \AA^{-1}(d=4.7 \AA), 0.36 \AA^{-1}(d=17.5 \AA)$ and $0.11 \AA^{-1}$ $(d=57.11 \AA)$. The meridional $4.7 \AA$ reflection corresponds to the spacing between hydrogen bonded $\beta$-strands that run perpendicular to the fibril axis. The equatorial $17.5 \AA$ reflection corresponds to a $\beta$-sheet network resulting from an alternated stacking of antiparallel peptides (spacing between the sheets). ${ }^{17}$ This inter-sheet distance is about twice that which is traditionally observed in typical amyloid fibers $(8-11 \AA)$. The reflection $a$ is actually the first oscillation generated by the scattering from a cylindrical shape as shown in Figure 3C, which displays the SAXS pattern of $10 \% \mathrm{WMDF}$ in $0.2 \mathrm{M} \mathrm{NaOH}$ and the corresponding fit. The fit was obtained by assuming a cylinder shape with a $47 \AA$ radius.

Figure 3D displays the azimuthal profiles of WMDF solutions in $0.2 \mathrm{M} \mathrm{NaOH}(\mathrm{pH} \mathrm{13})$ at concentrations ranging from 5 to $20 \%$ (traces 1-5). These scattering patterns were collected on the single detector of an in-house set-up. At concentrations below 10\%, the traces are barely distinguishable from the solvent (trace 0 ), except for a very weak bump around $0.2 \AA^{-1}$. From $10 \%$ and higher, the scattering strongly increases at the smallest angles, indicating the formation of large objects. As described above, the typical amyloid cross- $\beta$ fiber reflections are clearly visible. The correlation length $\xi$ estimated from the full width at half-maximum (FWHM) of the meridional and axial reflections with the relation $\xi=2 \pi / \mathrm{FWHM}$ is about $100 \AA$, which is of the order of the diameter of the fibrils observed in TEM (Figure 2D) and with the diameter of the cylinders used to fit the SAXS pattern (Figure 3C).

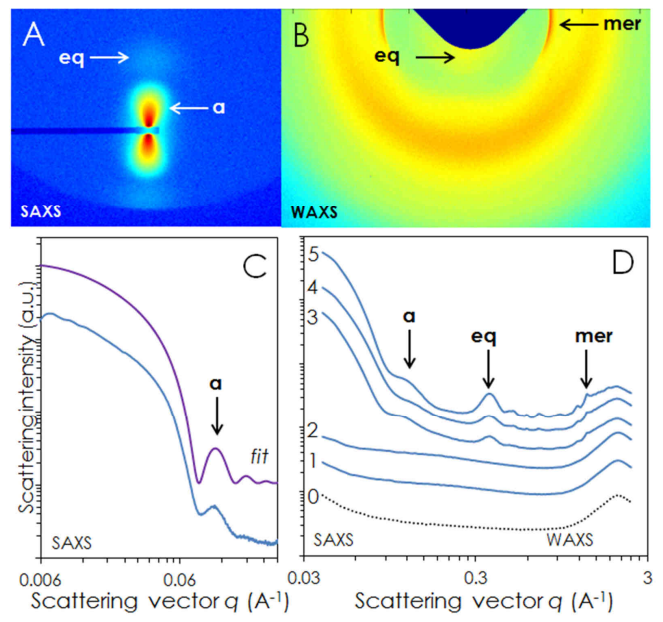

Figure 3: Small Angle X-Ray Scattering (SAXS) of WMDF gels solubilized in basic conditions. A-B) Oriented scattering pattern of $10 \%$ WMDF in $\mathrm{NH}_{4} \mathrm{Ac}$ (pH 11) on SAXS detector (A) and WAXS detector (B). The capillary and hence the fibrils were oriented horizontally. C) SAXS pattern of a 10\% WMDF gel solubilized in $0.2 \mathrm{M} \mathrm{NaOH}$ (blue line) and the corresponding fit assuming flexible cylinders (purple line). D) SAXS-WAXS patterns of WMDF solutions in $\mathrm{NaOH} 0.2 \mathrm{M}$ at different concentrations - 0: blank NaOH $0.2 \mathrm{M} ; 1$ : $5 \% ; 2: 7 \% ; 3: 10 \% ; 4: 15 \%$; 5 : $20 \%$. The arrows indicate the reflections corresponding to the meridional (mer) and equatorial (eq) orientations in respect with the fibrils' axis.

In Figure 4, the powder diffraction patterns of WMDF in acetic acid (trace 1) and PBS (trace 2) are displayed in comparison with the scattering pattern of $20 \% \mathrm{WMDF}$ in $\mathrm{NaOH}$ (trace 3 ). The diffraction patterns confirm the crystalline organization of the objects observed in Figure 2B. In addition to reflections attributed to amyloid structures, about 20 diffraction peaks are clearly visible in both patterns. Most peaks are common to both spectra, however there are still some differences that lead to slightly different cell parameters. Peak indexation trials led to the conclusion that both samples are polymorphic.In both cases, all cells are monoclinic and their parameters are rather close and consistent with the dimensions of the peptide monomer (See Table S1 in ESI). Their volumes $\left(V \sim 2300 \AA^{3}\right)$ suggest that they contain two peptides. These cells could not be linked to specific morphologies observed in TEM. Nevertheless, the correlation length $\xi$ estimated from the FWHM of the first four peaks is of the order of $1800 \AA$, which is about the lateral size of the elongated crystals observed in TEM (cf. Figure 2B).

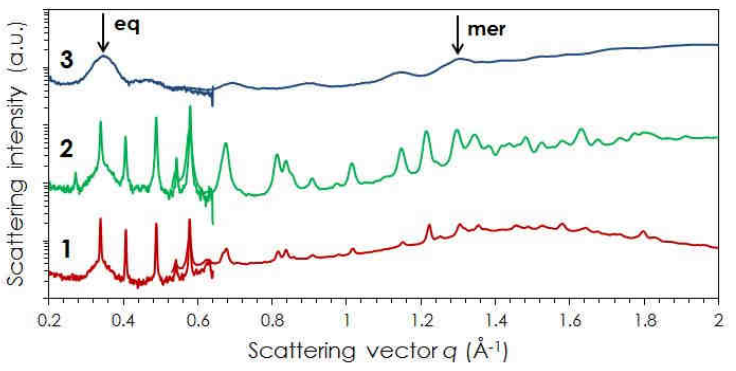

Figure 4: Diffraction patterns of crystallized WMDF. 1 (red line): Dried sample of WMDF prepared in acetic acid. 2 (green line): Crystals contained in a $10 \%$ WMDF gel prepared in PBS $(\mathrm{pH}$ 7.38) 3 (blue line): Concentrated solution $(20 \% \mathrm{w} / \mathrm{w})$ of WMDF fibrils prepared in $\mathrm{NaOH} 0.2 \mathrm{M}(\mathrm{pH}$ 13). The arrows labelled "eq" and "mer" indicate the position of the amyloid reflections. The overlap between the SAXS and WAXS detectors of the ID02 beamline, ESRF is seen in the $0.55-0.65 \AA^{-1}$ range.

Attenuated Total Reflection Fourier Transform Infrared (ATRFTIR) vibrations give information on the conformation of the peptide backbone in their assembled form. Figure 5A presents the area of the spectra corresponding to the amide vibrations which are the major characteristic bands of a peptide infrared spectrum. The amide I band, between 1600 and $1700 \mathrm{~cm}^{-1}$ is mainly associated with the $\mathrm{C}=\mathrm{O}$ stretching vibration and is directly related to the backbone conformation and the hydrogen bonding pattern. The amide II bands, between 1510 and $1580 \mathrm{~cm}^{-1}$, result from the $\mathrm{N}-\mathrm{H}$ bending vibrations and from the C-N stretching vibrations. ${ }^{39}$

After water spectrum subtraction and normalization, the amide I region is the part of the ATR-FTIR spectra that is the most characteristic of the peptide assembly (Figure 5A). At any $\mathrm{pH}$ 
tested, the spectra exhibit very thin and intense bands in the 16311645 range corresponding to a strong $\beta$-sheet structure. ${ }^{40,41} \mathrm{~A}$ satellite peak of lower intensity in the $1676-1684 \mathrm{~cm}^{-1}$ is indicative of an antiparallel organization. ${ }^{42}$ The fit of this region by Gaussian-Lorentzian peaks makes the change of conformation explicit as the $\mathrm{pH}$ increases (Figures S2 and S3). At acidic $\mathrm{pH}$ levels the vibration at $1643 \mathrm{~cm}^{-1}$ is the strongest and the vibration at $1627 \mathrm{~cm}^{-1}$ is barely detectable. As the $\mathrm{pH}$ increases, an inverse of the situation is observed as is illustrated in Figure S3. This shift of the main vibration is indicative of stronger hydrogen bonds and could be liken to the shift observed between transthyretin in native (1630-1643) and in fibril form (1611-1630). ${ }^{43,44}$ In both cases, these differences can be ascribed to the longer strand formation in fibrils versus native/crystal form. ${ }^{44}$ Yet, the increase in the intensity of bands assigned to unordered structures in $1650-1660 \mathrm{~cm}^{-1}$ suggests that amyloid fibrils are less structured than the microcrystals.

The amide II spectral region (Figure 5A) is rather independent of $\mathrm{pH}$, with a large band around $1550 \mathrm{~cm}^{-1}$ which mostly originates in $\mathrm{N}-\mathrm{H}$ vibrations. In each case, this part of the spectrum can be broadly deconvoluted by Gaussian functions (not shown) centered at $1497 \pm 2,1528 \pm 4,1546 \pm 2$ and $1558 \pm 4 \mathrm{~cm}^{-1}$ whose respective intensities can vary. The $1497 \pm 2 \mathrm{~cm}^{-1}$ band is very the likely ring vibrations of amino acids containing aromatic rings. ${ }^{45}$ Vibrations at 1528 and $1546 \mathrm{~cm}^{-1}$, which become prominent at basic $\mathrm{pH}$ levels, are attributed to the dominance of the bending of hydrogen bonded $\mathrm{NH}$ groups in antiparallel $\beta$-sheet structures. ${ }^{46}$

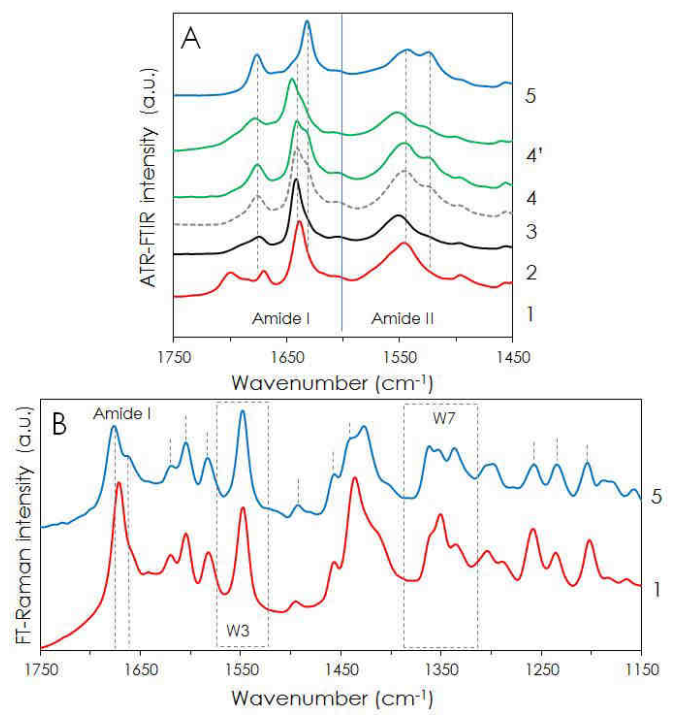

Figure 5: Vibrational spectroscopic characterization of WMDF solutions at different $\mathrm{pH}$ (amide I and amide II regions). A: ATRFTIR spectra. B) FT-Raman spectra. 1: WMDF solubilized in acetic acid $500 \mathrm{mM}$ (pH 2.4); 2: WMDF solubilized in pure water (pH 6.1); 3: WMDF solubilized in 5\% Mannitol (pH 6);4 and 4': $10 \% \mathrm{w} / \mathrm{w}$ WMDF solubilized in a $100 \mathrm{mM}$ phosphate buffer $(\mathrm{pH}$ 7); 5: $10 \%$ WMDF solubilized in a $200 \mathrm{mM} \mathrm{NaOH}$ solution ( $\mathrm{pH}$ 13.3). Raman peak attribution is shown in Supplementary Materials.

Finally, FT-Raman spectroscopy also offers fingerprints of the different conformations encountered in each condition (Figure 5B and Section 4of the ESI). The strong amide I peak at $\sim 1675 \mathrm{~cm}^{-1}$ once more confirms the formation of antiparallel $\beta$-sheet. However, because the peaks arising from tryptophan, phenylalanine and amide bands may overlap, exact attribution can be difficult. We propose attributions in the ESI (Table S2). Nevertheless, some qualitative conclusions may be drawn regarding the tryptophan environment. ${ }^{47,48}$ First, the W3 vibration is located at $1549 \mathrm{~cm}^{-1}$ in both acidic and basic conditions. The $\mathrm{W} 3$ vibration can be related to the torsion angle $\chi^{2,1}$ and defines the orientation of the indole ring with respect to the $\mathrm{C}-\alpha$ atom of the amino acid backbone ${ }^{49}$ and in both acidic and basic conditions $\chi^{2,1} \approx 90^{\circ}$. Likewise, the $\mathrm{W} 17$ vibration at $876 \mathrm{~cm}^{-1}$ at both $\mathrm{pH}$ (ESI, Figure S4C), indicates that the indole $\mathrm{N}-\mathrm{H}$ is involved in a medium-strength hydrogenbond as is formed with solvent water. The intensity ratio of the W7 Fermi doublet $\left(I_{1360} / I_{1340}\right)$ is also reported to depend on the hydrophilic/hydrophobic tryptophan environment. With ratios of 1.5 and 1.26 at acidic and basic conditions respectively, it can be inferred that tryptophan environment is only moderately hydrophobic.

The tryptophan environment can also be assessed by steadystate fluorescence spectroscopy. Figure S5 (ESI) shows that the tryptophan environment is rather polar, even when the peptides are aggregated into fibrils or microcrystals. In the latter cases the average $\lambda_{\max }$ is about $350 \mathrm{~nm}$, which is similar to the values given for an exposed tryptophan in a protein. Values reported for buried tryptophan residues are closer to $330 \mathrm{~nm} .{ }^{50}$ However, this value is significantly shifted with respect to the ones measured for the monomers in solutions $(366 \mathrm{~nm})$ which are similar to those reported for the amino acid alone in solution. ${ }^{51}$ As for the intensity of the emission peak, it decreases as the proportion of assembled peptides increases.

Overall, there is a set of evidence pointing towards an antiparallel arrangement of the peptides in the different morphologies found. Despite an expected hydrophobic-driven self-assembly, it appears that the tryptophan residue is not fully buried in the supramolecular structure but may be involved in hydrogen bonding rather than in $\pi$-stacking. Calculations of contact potentials between two adjacent peptides are also in favor of antiparallel structures where the backbone would be staggered by three amino acids (See ESI, Figure S1), an arrangement that allows hydrophobic interactions between phenylalanine residues, but not for tryptophan residues as suggested by Raman and fluorescence spectra. $\mathrm{X}$-ray diffraction analyses also suggest that in spite of a polymorphism at the molecular level, molecules are always packed in a similar kind of unit cell; the conformational differences detected as a function of $\mathrm{pH}$ would then only arise from different lateral chain organizations. Additional characterization with solid-state nuclear magnetic resonance ${ }^{52,53}$ could probably confirm the proximities between residues.

Here, we have demonstrated that even a small fragment of Cholecystokinin are able to self-assemble into amyloid structures even though aggregation propensities predictions are null for this specific amino acid sequence for most algorithms ${ }^{54-57}$ (see Figure S6A-D in ESI). Nevertheless, both Aggrescan ${ }^{58}$ and Zyggregator ${ }^{59}$ predict aggregation (Figure S6E-F). Prior experimental work on gastrin related peptides by Oakley et al. had reported fibril formation at $0.5 \% \mathrm{w} / \mathrm{w}$ in saline solution. ${ }^{60}$ Notably, they also mentioned that "fibrils not only disaggregate completely after mild alkali treatment but the peptide also fails to form fibrils at a high $\mathrm{pH}$ ". We have clearly demonstrated that this is not the exact case. The critical aggregation concentration simply increases with $\mathrm{pH}$. It is probably the sheer shortness of the sequence that makes the morphology extremely sensitive to $\mathrm{pH}$, especially at $\mathrm{pH}$ levels close to physiological conditions. However, as $\mathrm{Hu}$ et al. have pointed out in the case of Pmel17:RPT, functional amyloids do not necessarily require a specific structure or morphology. ${ }^{61}$ In the present case, if we assume a storage end, there is indeed no need 
for a very regular structure; only packing density and reversibility are required.

\section{Assessment of the reversible nature of the amyloid as- semblies of WMDF.}

One of the primary hypotheses about functional amyloids fibrils that are assumed to serve as storage means is that this type of supramolecular assembly must be reversible. In this respect, WMDF hydrogels were shown to be easily solubilized upon dilution. However, given the detection threshold of our analytical techniques it is difficult to prove that the fibrils themselves are disassembled and not simply dispersed in a solution of larger volume. To keep the peptide concentration constant during the putative disassembly process, basic solutions of WMDF were submitted to acid vapors (either glacial acetic acid or hydrogen chloride vapors). Conversely, acidic or neutral solutions were submitted to (basic) ammonia vapors.

In most cases, it is macroscopically clear that the sample is undergoing drastic changes: initially whitish and light scattering acid samples containing microcrystals and larger aggregates rapidly clear up (Figure 6 A-B), while liquid (at concentrations below $10 \% \mathrm{w} / \mathrm{w}$, Figure $6 \mathrm{C}-\mathrm{D}$ ) or gel basic samples (at concentrations above $10 \%$ w/w, Figure 6 E-F) precipitate. ATR-FTIR and SAXS characterizations confirm the optical observations. Figure 6A shows an initially well-structured spectrum of an acidic sample (red line) transformed into a weak disordered spectrum (blue line) after said sample has been submitted to basic ammonia vapors. Corresponding SAXS spectra show diffraction peaks (red line) disappearing (blue line) as well as intensity decreasing at smaller angles indicating the disappearance of large objects in the solution (Figure 6B). However, the scattering pattern is indicative of cylindrical shapes (fibrils) in solution. Conversely, Figure 6C-D show non structured spectra of a low concentration basic sample (blue lines) transformed into structured spectra (red lines) as $\mathrm{pH}$ is decreased with acetic acid vapors. The characteristic vibration bands or diffraction peaks correspond to those described in previous section for crystal structures obtained directly in water or acetic acid. SAXS spectra also clearly shows an increase in scattering intensity corresponding to the formation of large supramolecular objects (Figure 6D). The non-structured spectra correspond to solutions containing non-assembled solubilized WMDF monomers. Finally, Figure $6 \mathrm{E}$ illustrates the transition from a structured FTIR spectrum (blue line) corresponding to a fibrillar assembly to a structured spectrum (red line) corresponding to a crystalline structure. Here again, the spectral modifications are in line with the differences observed in Figure 5 for both amide I and amide II bands. The changes in SAXS patterns (Figure 6F), in this case, are not drastic although we observe a clear increase of diffraction peak intensity indicating growth of the crystalline phase as $\mathrm{pH}$ level decreases.

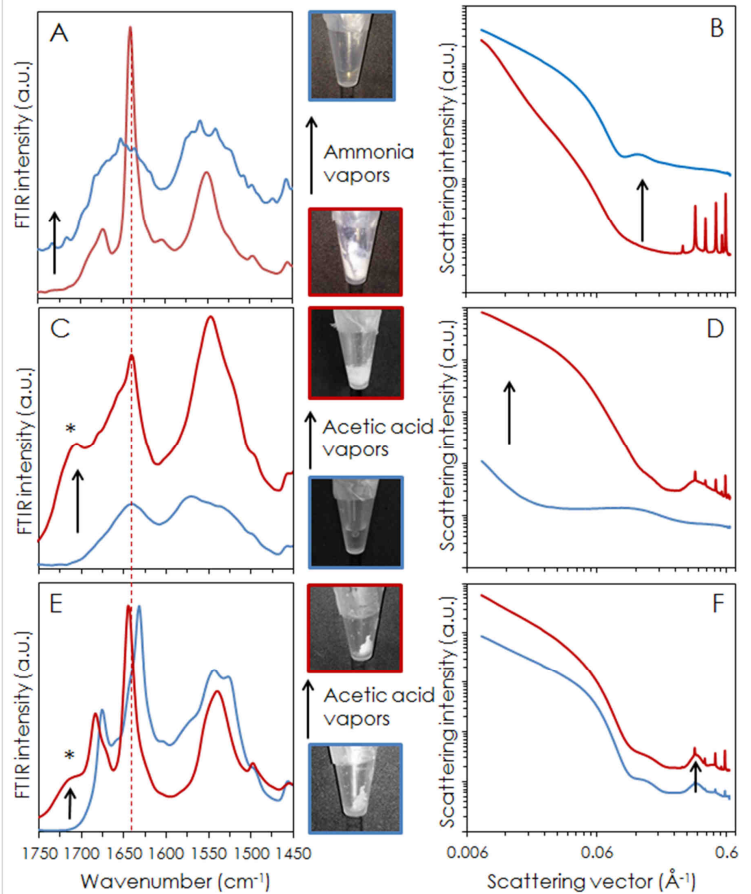

Figure 6: Structural characterization of WMDF samples before and after $\mathrm{pH}$ change. A-B) 5\% WMDF solubilized in water (red line) then submitted to ammonia vapors (blue line). C) $5 \%$ WMDF solubilized in $0.2 \mathrm{M} \mathrm{NaOH}$ (blue line) then submitted to glacial acetic acid vapors (red line). D) 9\% WMDF solubilized in $0.2 \mathrm{M} \mathrm{NaOH}$ (blue line) then submitted to glacial acetic acid vapors (red line). E) $13 \%$ WMDF solubilized in $0.2 \mathrm{M} \mathrm{NaOH}$ (blue line) then submitted to glacial acetic acid vapors. F) $15 \%$ WMDF solubilized in $0.2 \mathrm{M} \mathrm{NaOH}$ (blue line) then submitted to glacial acetic acid vapors. The spectra have been shifted for clarification. The stars $(*)$ in the FTIR spectra indicate the peak arising from acetic acid in the solution. In the middle panels pictures of the corresponding samples stored in Eppendorf tubes are shown.

In Figure 7 we show examples of microscopic investigations with TEM. Initially, the sample is typical of a poorly solubilized WMDF solution with aggregates and crystals (Figure 7A1), which is consistent with the light scattering seen by the naked eye. When basified with ammonia vapor $(\mathrm{pH}>11)$, fibrils appear (Figure 7A2), in agreement with observations made with samples directly prepared in $\mathrm{NaOH}$, albeit some remaining aggregates can be found. Conversely, Figure 7B exhibits a gelated sample initially solubilized in $\mathrm{NaOH}$. When submitted to hydrochloride vapors, the sample becomes more liquid and finally turns blue, which is possibly due to oxidation of part of the sample by the strong acid. In contrast, samples acidified with acetic acid vapours remain uncolored. Transmission electron micrographs show that the fibrils initially structuring the gel (Figure 7B1) have completely disappeared and been replaced by large aggregates of crystals (Figure 7B2), which is coherent with other samples characterized with FTIR and SAXS that did not turn blue. 

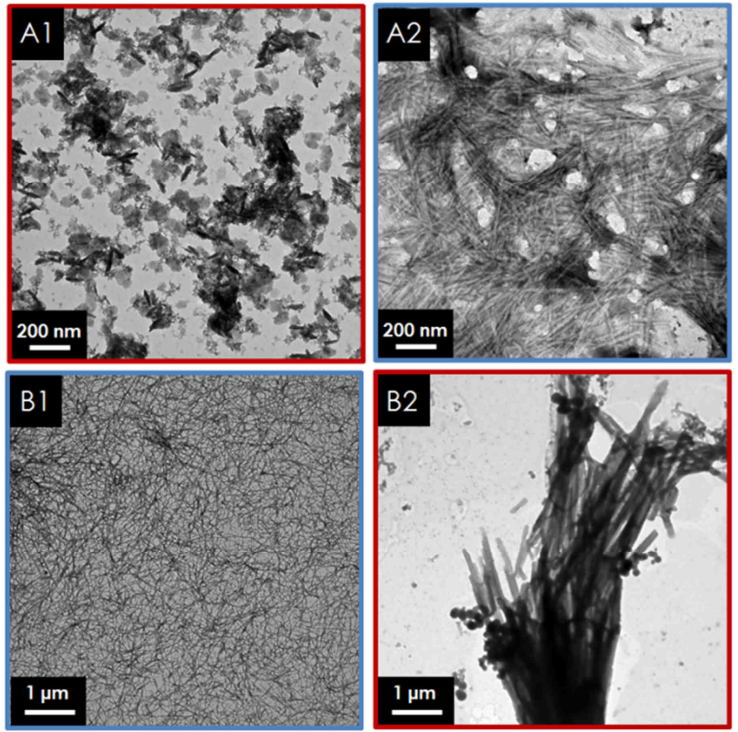

Figure 7: Transmission Electron Micrographs of A1) A trouble solution of WMDF solubilized in PBS; A2) the same sample after 10 minutes in ammonia vapors; B1) a fibrillar gel of WMDF solubilized $\mathrm{NaOH} 0.2 \mathrm{M}$; B2) the same sample after 10 minutes in $\mathrm{HCl}$ vapors. Scalebars $=200 \mathrm{~nm}$ (Panels A) and $1 \mu \mathrm{m}$ (Panels B).

Overall, these observations prove that both morphologies described in this study are reversible with $\mathrm{pH}$ and can be turned into one another. Additionally, the formation of microcrystals from fibrils refutes the idea that the crystals observed in the samples directly prepared at low $\mathrm{pH}$ are simply the unsolubilized remains of the powder or the result of nonspecific aggregation that would compete with fibril formation. Given the higher solubility of the peptide at high $\mathrm{pH}$, increasing the $\mathrm{pH}$ can also lead to complete dissolution of supramolecular assemblies.

This reversible feature is not so common. It is indeed usually reported that amyloid fibrils are insoluble, very resistant and only disappear under very harsh denaturing conditions. Moreover, after that treatment, no newly formed fibrils would form again. Previously, Kurouski et al. ${ }^{62}$ have observed that apo- $\alpha$-lactalbumin fibrils spontaneously refold from one polymorph to another as a result of salt removal and drop of temperature. However, the WMDF system is more comparable with other self-assembling peptides whose sequence also comes from hormones and that also simply disappear upon dilution. Such behavior was observed with Lanreotide (a synthetic analogue of somatostatine) nanotubes that disassemble upon dilution or melt as temperature is increased while retaining their ability to reform nanotubes ${ }^{63}$ or $\beta$-endorphin amyloid fibrils. ${ }^{64}$ Triptorelin (a synthetic analogue of $\mathrm{GnRH}$ ) also exhibits different morphologies with $\mathrm{pH}^{19}$

\section{Charge modification by amino-acid exchange and further discussion on the role of charges.}

As other studies have illustrated, charges and counterions play a crucial role in supramolecular assemblies (see Gobeaux et al. and references herein). ${ }^{65}$ It is also anticipated that this role is all the more crucial here that the sequence is short. As expected, modifying one charge, i.e. replacing the aspartic acid (D) in the third position - whose side chain is negatively charged at basic $\mathrm{pH}-$ by an uncharged asparagine residue $(\mathrm{N})$, has a direct effect on solubility and assembling properties of the peptide. Indeed, at basic $\mathrm{pH}$ levels, where the net charge of the WMNF is zero (Figure 1B), the peptide is now poorly soluble. On the other hand, at acidic $\mathrm{pH}$ levels, WMNF is much more soluble that WMDF despite the fact that they exhibit the same net charge. As can been seen on TEM images (Figure 8), the modification also has a direct effect on the morphology of the objects formed at all pHs. In pure water, WMNF spontaneously forms long, unbranched fibrils of about $12 \mathrm{~nm}$ wide (Figure 8A). With a better resolution (Figure 7B), one can perceive a substructure suggesting that the fibrils are composed of two $6 \mathrm{~nm}$ wide fibrils. For solutions prepared in 150 $\mathrm{mM}$ acetic acid, the supramolecular assemblies take the form of long twisted ribbons (Figure 8C-D) whose width may vary between 25 and $80 \mathrm{~nm}$. A plot of the twist period as a function of the width of the ribbons, taken from 83 individual measurements, suggests a correlation (see inset in Figure 8D). Macroscopically, the entanglement of these ribbons form birefringent gels. At acidic $\mathrm{pH}$ levels the fibrils and ribbons all exceed ten microns in length. Whereas at neutral or basic $\mathrm{pH}$ levels, the objects formed appear more thickset (Figure 8E-F for $100 \mathrm{mM}$ PBS). They rarely exceed one micron and have an aspect ratio ranging from 5 to 15 . Interestingly, these objects are also twisted (black arrows, Figure $8 \mathrm{~F}$ ), albeit not more than one twist is observed on each object.
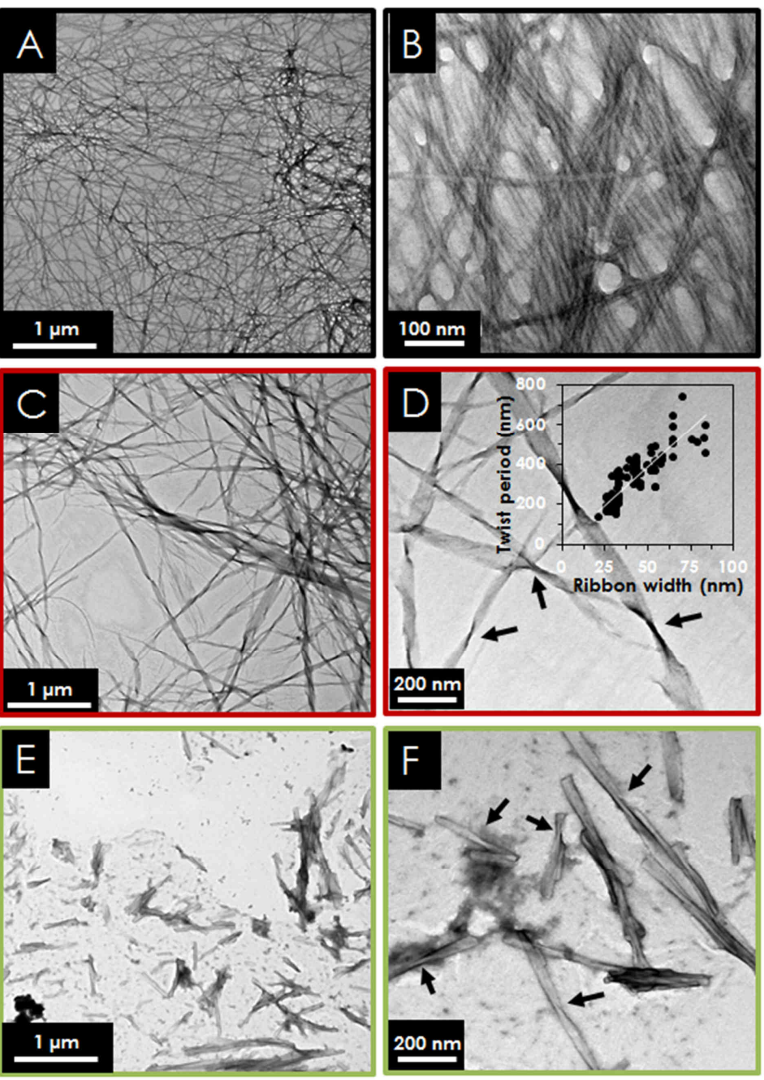

Figure 8: Transmission electron micrographs of WMNF solubilized in water (A-B), $150 \mathrm{mM}$ acetic acid (C-D) and $100 \mathrm{mM}$ PBS (E-F). Inset in panel D shows the plot of the period between two twists (as indicated by arrows in panel D) as the function of the ribbon width in acidic conditions. The linear regression yields a slope of 7.7 with a coefficient of determination $R^{2}$ of 0.6824 .

The ATR-FTIR spectra (Figure 9A) indicate a strong and uniform structure and organization into $\beta$-sheets: all spectra exhibit a strong peak around $1640 \mathrm{~cm}^{-1}$ with a FWHM lower than $20 \mathrm{~cm}^{-1}$ (the fitted Lorentzian-Gaussian peaks yield values between 11 and $\left.14 \mathrm{~cm}^{-1}\right)$. At all pHs tested up to 7.4, the main peak is located at $1641.8 \mathrm{~cm}^{-1}$. In $\mathrm{NaOH}(\mathrm{pH} \sim 13)$, it shifts to $1639.2 \mathrm{~cm}^{-1}$. Other 
peaks traditionally attributed to $\beta$-sheets are also observed at 1627 and $1685 \mathrm{~cm}^{-1}$, which again suggests an antiparallel organization of the $\beta$-sheets. Finally, another peak is detected at $1662 \mathrm{~cm}^{-1}$ that can be attributed to disorder. The peaks in the amide II region (1500-1600 $\mathrm{cm}^{-1}$ ) do not change with $\mathrm{pH}$ and differences with those observed in the WMDF spectra are minor.

The SAXS characterization of the WMNF solutions also points towards a $\beta$-sheet organization. At both $\mathrm{pHs}$ tested, the equatorial and meridional reflections of the cross $\beta$-sheet are detected. However, the structures formed at a low $\mathrm{pH}$ are a lot more organized than those formed at higher pHs. Here, the scattering curve corresponding to the sample prepared in PBS only shows a few reflections and an increasing scattering at low $q$ indicating the presence of large, polydisperse scattering objects. The meridional reflection at $1.25 \AA^{-1}$, indicates an average interstrand spacing of about $5 \AA$, a slightly higher value than the $4.7 \AA$ commonly reported. The $11.7 \AA$ spacing between the sheets corresponding to the equatorial reflection is a more typical value. By contrast, the scattering curves of WMNF in acetic acid suggest a more regular structuration. The meridional reflection at $1.31 \AA^{-1}(4.79 \AA)$ indicates a tighter packing of the peptide strands. The strong correlation peak $0.0296 \AA^{-1}(\sim 212 \AA)$ is characteristic of interactions between the scattering objects while the oscillations indicate their size monodispersity. The red curves are taken along the capillary and show that the sample is not homogeneous, probably because of sedimentation, and that the correlation peak disappears readily as the fibril concentration decreases. The curves without the correlation peak can be reasonably fitted by a cylindrical form factor. The fitted radius is about $5.2 \mathrm{~nm}$, which is of the same order of magnitude than the radius of the objects observed by TEM in Figure 8A-B.

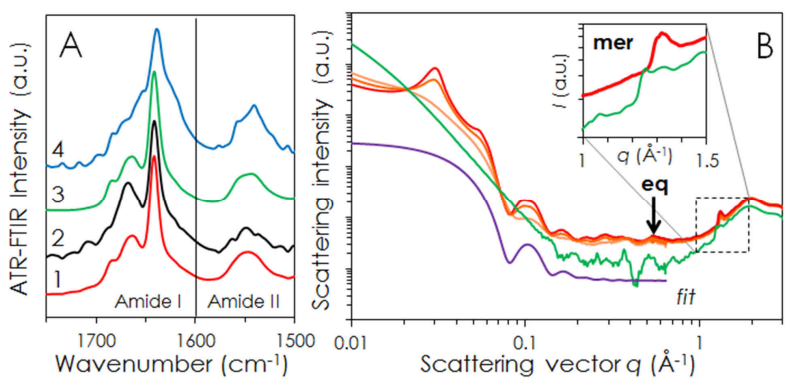

Figure 9: Characterization of the WMNF gels. A) Amide I \& II regions of the ATR-FTIR spectra of $10 \% \mathrm{w} / \mathrm{w}$ WMNF solutions solubilized in $0.2 \mathrm{M}$ acetic acid (1), water (2), 0.1 M PBS (3) and $0.2 \mathrm{M} \mathrm{NaOH}$ (4). B) SAXS-WAXS patterns of $10 \%$ WMNF gels in acetic acid (red lines) and in PBS (green line). A fit of the SAXS part assuming a cylindric shape is plotted in purple. The noise in the $0.2-0.8 \AA^{-1}$ range appeared with the subtraction of the kapton cell scattering. The insert is a blow-up of the interstrand amyloid peak plotted on a linear scale.

\section{Phase Diagram.}

From the multiple conditions that we have tested, it emerges that there is a fine balance between the solubility of the peptide and its self-assembly properties. For example, at $\mathrm{pH} \mathrm{11,} \mathrm{the} \mathrm{criti-}$ cal assembly concentration is lower than at $\mathrm{pH} 13(\sim 3 \%$ vs $\sim 10 \%)$ where the WMDF monomer is highly soluble because of its net charge. Likewise, the assembly/gelification process is faster at $\mathrm{pH}$ 11. In the case of the WMNF peptide, it is interesting to note that the excellent solubility of the asparagine amino acid (which is 5 times higher than that of aspartic acid in water) is transferred to the whole peptide sequence. However, as emphasized by Do et $a l .{ }^{66}$, the terminal net charge is very important in regulating solubility and assembly. In the present case, it appears to be essential. Indeed, when the $\mathrm{N}$-terminus is deprotonated at basic $\mathrm{pH}$ levels, the WMNF solubility is poor, while in the case of WMDF the deprotonation of the aspartic acid balances the high hydrophobicity of the aromatic-rich sequence.

Additionally, the peptides themselves contribute to the solutions buffering and there is a complex feedback between the $\mathrm{pH}$ of the solutions, the state of charge of the peptides and their state of assembly. ${ }^{65}$ As a consequence, at high peptide concentrations the $\mathrm{pH}$ might be slightly different than at lower concentrations. As we have seen, the morphology of the WMDF and WMNF supramolecular assemblies are sensitive to the $\mathrm{pH}$ of the solution. This explains why in some cases the morphology observed in TEM does not exactly match that inferred from SAXS measurement for the same buffer. Indeed, the concentration of solutions needed for TEM observations are significantly lower than that necessary to obtain a good X-ray scattering signal. Likewise, the polymorphism and variable solubility observed when WMDF is solubilized in PBS ( $\mathrm{pH}$ 7.4) may be attributed to its complex zwitterionic nature. Indeed, at high concentrations, it is possible that the peptides compensate their charges two-by-two. The resulting dimers would then further associate in many different ways in absence of uncompensated charges to direct the assembly with charge repulsion. This mechanism would then lead to the formation amorphous aggregates. ${ }^{67}$

Our observations are summarized in the phase diagram Figure 10 and in Table 1. There are basically four zones: (a) a microcrystal phase at low $\mathrm{pH}$, (b) a non-assembled phase at high $\mathrm{pH} / \mathrm{low}$ concentration, (c) a fibrillar phase at high $\mathrm{pH} /$ high concentration and (d) coexisting fibrils and crystals at intermediate $\mathrm{pH} /$ intermediate concentrations and high $\mathrm{pH} / \mathrm{very}$ high concentrations. Table 1 compares the solubility, morphology and net charge of WMDF and WMNF at three different $\mathrm{pH}$ levels. For simplicity, we have only discussed the influence of the $\mathrm{pH}$. However, we have used different buffers and we cannot exclude that the different type of ions can play a role in the assembly properties.

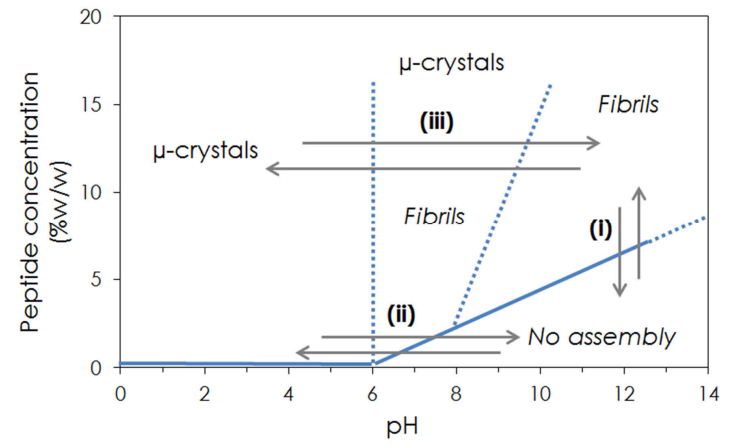

Figure 10: Phase diagram of WMDF. As pH level increases, the peptide solubility increases. Additionally, morphology changes from microcrystals at low $\mathrm{pH}$ to classic amyloid fibrils at higher pHs. The possible scenarios for hormone release, either by dilution (path (i)) or $\mathrm{pH}$ change (path (ii)) are illustrated by yellow arrows. Path (ii) corresponds to the experiment presented in Figure 6A-B and Figure 6C-D and path (iii) to the experiment presented in Figure 6E-F. 
Table 1: Summary comparing WMDF and WMNF assembly properties at three $\mathrm{pH}$ levels.

\begin{tabular}{|c|c|c|c|}
\hline & & WMDF & WMNF \\
\hline 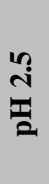 & $\begin{array}{l}\text { Net charge } \\
\text { Solubility } \\
\text { Morphology }\end{array}$ & $\begin{array}{c}(+) \text { WMDF } \\
+1 \\
\text { Bad } \\
\text { nanocrystals }\end{array}$ & $\begin{array}{c}(+) \text { WMNF } \\
+1 \\
\text { Good } \\
\text { Fibrils }\end{array}$ \\
\hline $\begin{array}{l}\stackrel{+}{r} \\
\text { 吾 }\end{array}$ & $\begin{array}{l}\text { Net charge } \\
\text { Solubility } \\
\text { Morphology }\end{array}$ & $\begin{array}{c}(+) \mathbf{W M D}(-) \mathbf{F} \\
0 \\
\text { Mediocre } \\
\text { Nanocrystals/fibrils }\end{array}$ & $\begin{array}{c}(+) \mathbf{W M N F} \\
+1 \\
\text { Good } \\
\text { Twisted ribbons }\end{array}$ \\
\hline$\frac{2}{2}$ & $\begin{array}{l}\text { Net charge } \\
\text { Solubility } \\
\text { Morphology }\end{array}$ & $\begin{array}{c}\text { WMD }(-) \mathbf{F} \\
-1 \\
\text { Good } \\
\text { Fibrils }\end{array}$ & $\begin{array}{c}\text { WMNF } \\
0 \\
\text { Mediocre } \\
\text { Twisted aggregates }\end{array}$ \\
\hline
\end{tabular}

\section{Biological implications.}

Although most of the conditions explored in our in vitro study can be considered to be far from physiological conditions, some lessons can be drawn from our observations.

First, as observed with other protein hormones ${ }^{16,68,69,70}$, the CCK-4 aggregates are very likely to be used as storage means in secretory vesicles in which they undergo post-translational processing. ${ }^{71}$ There are indeed several advantages to storage into reversible amyloid structures. The most obvious advantage is to reach high concentrations in small volumes while keeping an isoosmotic relationship with the surrounding cytoplasm. Furthermore, an assembled form might be able to oppose the lysis or at least to slow it down. Indeed, it has been measured that the CCK4 half-life in human plasma is 13 minutes. ${ }^{72}$ As noted by Dannies, aggregation is also an economical means of sorting because selfassociation removes the hormones from other possible pathways. ${ }^{68}$

Secondly, the influence of concentration and $\mathrm{pH}$ on the aggregation may provide explanations on how CCK-4 neuro-hormones are released in vivo. Indeed, it has been proposed that vesicles containing aggregated hormones fuse with plasma membrane, so their dense-cores are released and dissolve, causing a burst of hormone in the bloodstream on a timescale much faster than could result from increasing synthesis. ${ }^{68}$ If we consider the approximate phase diagram drawn from our observations (Figure 10), two dissolution mechanisms are possible: either by simple dilution (i) or by a small shift in $\mathrm{pH}$ that would allow shifting from aggregated form to the unassembled form at a fixed concentration (ii). This would be consistent with the literature that reports slightly acidic $\mathrm{pH}$ levels in secretory granules (low c.a.c) and higher $\mathrm{pH}$ level in the plasma in which the hormones are released (higher c.a.c). Admittedly, we see no biological relevance to path (iii) except that it demonstrates the reversibility of both the assembled forms. Even though the microcrystal morphology may at first seem unlikely to be encountered in vivo' it has been reported that in certain conditions insulin is stored as microcrystals in densecore secretory granules. ${ }^{73,74}$ As mentioned above, there is no monomorphism requirement for a storage purpose. What is more, microcrystal suspensions can be envisioned as an easily syringeable drug formulation that would release monomers when dissolved in physiological conditions. ${ }^{75}$
Thirdly, by working with solutions reaching up to $20 \% \mathrm{w} / \mathrm{w}$ (> $200 \mathrm{mg} / \mathrm{mL}$ ) we are closer to the crowding in cells ${ }^{76,77}$ than most in vitro studies that use solution concentrations around $2 \mathrm{mg} / \mathrm{mL}$. Concentrations in dense core granules might even reach higher values. ${ }^{78,79}$ Further studies should try to mimic the in vitro condition in terms of salt composition (multivalent ions) and cosolutes like glycoaminoglycans that have been reported to increase aggregation and could also have an effect on supramolecular aggregates morphology. However, in this study we have favored "extreme" and somewhat unrealistic salt and $\mathrm{pH}$ conditions. Indeed, since we hypothesized that the different morphologies were guided by the state of charge, we tried to reduce polymorphism by working at $\mathrm{pH}$ levels far from the peptide $\mathrm{pK}_{\mathrm{a}} \mathrm{s}$.

Finally, although the present study does not deal with kinetics (we will report thorough kinetic measurements in a forthcoming article), we have observed that aggregation and gelification usually happens within a few hours if not minutes which is also coherent with what would be a functional behavior in vivo. For example prolactin, whose secretory pathway has been studied in details, is detected in aggregates only 30 minutes after synthesis. ${ }^{68}$

\section{CONCLUSION}

In conclusion, the reported results show that even a short peptide sequence can hold well-defined and controllable assembly properties. With only four amino-acids in its sequence the Cholecystokinin/Gastrin tetrapeptide (aka WMDF or CCK-4) can attain different conformations that lead to polymorphic supramolecular assemblies. By using rather extreme $\mathrm{pH}$ conditions, we show that it is possible to choose one or the other morphology. Furthermore, the formation of these morphologies is reversible upon $\mathrm{pH}$ modification. We also show that the charge modification obtained by replacing the aspartic acid by asparagine is able to modify the morphology of the amyloid. Finally, although we have little in vivo data specific to CCK-4 to compare with our in vitro results, the behavior and phase diagram of CCK-4 aggregation are compatible with the requirements for a storage application. Further studies will examine the kinetics of formation and release of these thermodynamically-driven fibrils structures and hopefully bring new information on the generic mechanisms of amyloid assembly.

\section{AUTHOR INFORMATION}

\section{Corresponding Author}

*frederic.gobeaux@cea.fr

\section{Funding Sources}

This research did not receive any specific grant from funding agencies in the public, commercial, or not-for-profit sectors.

\section{ASSOCIATED CONTENT}

Supporting Information Available. Diffraction peaks indexation of WMDF in acetic acid and PBS with corresponding cell parameters. Contact potential estimations. WMDF FTIR fits. Full FT-Raman plot and peak attribution table. ThT fluorescence assays. Steady state fluorescence study. Amyloidogenicity predictions with online tools. WMNF FTIR amide I fit.

This information is available free of charge via the Internet at http://pubs.acs.org.

\section{ACKNOWLEDGMENTS}


Maïté Paternostre is gratefully acknowledged for funding the purchase of the first batch of peptide as is the LIONS for the financial support. We thank Hannah Rapaport, Corinne Chevallard and Patrick Guenoun for discussions and reading the first draft of the manuscript. Andrew Gall is thanked for access to Raman spectrometer. TEM observations were performed at the "TEM-team" platform (iBiTec-S/SB2SM). SAXS-WAXS experiments reported in Figure 3A-B, Figure 4, Figure 6B-D-F and Figure 9B were performed on beamline ID2 at the European Synchrotron Radiation Facility (ESRF), Grenoble, France. We are also grateful to Sylvain Prevost for his assistance. The SAXSWAXS experiments reported in Figure $3 \mathrm{C}$ and preliminary data were collected on the in-house MOMAC set-up, funded by RTRA "Triangle de la Physique".

This work benefited from the use of the SasView application, originally developed under NSF award DMR-0520547. SasView contains code developed with funding from the European Union's Horizon 2020 research and innovation programme under the SINE2020 project, grant agreement No 654000 .

\section{REFERENCES}

(1) Chiti, F.; Dobson, C. M. Protein Misfolding, Functional Amyloid, and Human Disease. Annu Rev Biochem 2006, 75, 333-366.

(2) Hamley, I. W. The Amyloid Beta Peptide: A Chemist's Perspective. Role in Alzheimer's and Fibrillization. Chem. Rev. 2012, 112 (10), 5147-5192.

(3) Hoyer, W.; Antony, T.; Cherny, D.; Heim, G.; Jovin, T. M.; Subramaniam, V. Dependence of $\alpha$-Synuclein Aggregate Morphology on Solution Conditions. J. Mol. Biol. 2002, 322 (2), 383-393.

(4) Fowler, D. M.; Kelly, J. W. Functional Amyloidogenesis and Cytotoxicity-Insights into Biology and Pathology. PLoS Biol. 2012, 10 (12), e1001459.

(5) Iconomidou, V. A.; Vriend, G.; Hamodrakas, S. J. Amyloids Protect the Silkmoth Oocyte and Embryo. FEBS Lett. 2000, 479, 141-145.

(6) Iconomidou, V. A.; Hamodrakas, S. J. Natural Protective Amyloids. Curr. Protein Pept. Sci. 2008, No. 9, 291-309.

(7) Gras, S. L.; Tickler, A. K.; Squires, A. M.; Devlin, G. L.; Horton, M. A.; Dobson, C. M.; MacPhee, C. E. Functionalised Amyloid Fibrils for Roles in Cell Adhesion. Biomaterials 2008, 29 (11), 1553-1562.

(8) Watt, B.; van Niel, G.; Raposo, G.; Marks, M. S. PMEL: A Pigment Cell-Specific Model for Functional Amyloid Formation. Pigment Cell Melanoma Res. 2013, 26 (3), 300-315.

(9) Otzen, D. Functional Amyloid: Turning Swords into Plowshares. Prion 2010, 4 (4), 256-264.

(10) Mostaert, A. S.; Higgins, M. J.; Fukuma, T.; Rindi, F.; Jarvis, S. P. Nanoscale Mechanical Characterisation of Amyloid Fibrils Discovered in a Natural Adhesive. J. Biol. Phys. 2007, 32 (5), 393-401.

(11) Garcia-Sherman, M. C.; Lundberg, T.; Sobonya, R. E.; Lipke, P. N.; Klotz, S. A. A Unique Biofilm in Human Deep Mycoses: Fungal Amyloid Is Bound by Host Serum Amyloid P Component. NPJ Biofilms Microbiomes 2015, 1 .

(12) Fowler, D. M.; Koulov, A. V.; Balch, W. E.; Kelly, J. W. Functional Amyloid - from Bacteria to Humans. Trends Biochem. Sci. 2007, 32 (5), 217-224.

(13) Romero, D.; Kolter, R. Functional Amyloids in Bacteria. Int. Microbiol. 2014, 17 (2), 65-73.
(14) Fowler, D. M.; Koulov, A. V.; Alory-Jost, C.; Marks, M S.; Balch, W. E.; Kelly, J. W. Functional Amyloid Formation within Mammalian Tissue. PLoS Biol. 2006, 4 (1), e6.

(15) Podlubnaya, Z. A.; Bobylev, A. G. On Functional Amyloids of Muscle Proteins of Titin Family. Biophysics 2012, 57 (5), 577-580.

(16) Maji, S. K.; Perrin, M. H.; Sawaya, M. R.; Jessberger, S.; Vadodaria, K.; Rissman, R. A.; Singru, P. S.; Nilsson, K. P. R.; Simon, R.; Schubert, D.; et al. Functional Amyloids As Natural Storage of Peptide Hormones in Pituitary Secretory Granules. Science 2009, 325 (5938), 328332.

(17) Valéry, C.; Paternostre, M.; Robert, B.; Gulik-Krzywicki, T.; Narayanan, T.; Dedieu, J.-C.; Keller, G.; Torres, M.L.; Cherif-Cheikh, R.; Calvo, P. Biomimetic Organization: Octapeptide Self-Assembly into Nanotubes of Viral Capsid-like Dimension. Proc. Natl. Acad. Sci. 2003, 100 (18), 10258-10262.

(18) Valéry, C.; Artzner, F.; Paternostre, M. Peptide Nanotubes: Molecular Organisations, Self-Assembly Mechanisms and Applications. Soft Matter 2011, 7 (20), 9583.

(19) Valéry, C.; Deville-Foillard, S.; Lefebvre, C.; Taberner, N.; Legrand, P.; Meneau, F.; Meriadec, C.; Delvaux, C.; Bizien, T.; Kasotakis, E.; et al. Atomic View of the Histidine Environment Stabilizing Higher-pH Conformations of pH-Dependent Proteins. Nat. Commun. 2015, 6, 7771.

(20) Tarabout, C.; Roux, S.; Gobeaux, F.; Fay, N.; Pouget, E.; Meriadec, C.; Ligeti, M.; Thomas, D.; IJsselstijn, M.; Besselievre, F.; et al. Control of Peptide Nanotube Diameter by Chemical Modifications of an Aromatic Residue Involved in a Single Close Contact. Proc. Natl. Acad. Sci. 2011, 108 (19), 7679-7684.

(21) Hutchinson, J. A.; Burholt, S.; Hamley, I. W. Peptide Hormones and Lipopeptides: From Self-Assembly to Therapeutic Applications: Peptides: From Self-Assembly to Therapeutic Applications. J. Pept. Sci. 2017.

(22) Panda, J. J.; Chauhan, V. S. Short Peptide Based SelfAssembled Nanostructures: Implications in Drug Delivery and Tissue Engineering. Polym. Chem. 2014, 5 (15), 4431.

(23) Doll, T. A. P. F.; Raman, S.; Dey, R.; Burkhard, P. Nanoscale Assemblies and Their Biomedical Applications. J. R. Soc. Interface 2013, 10 (80), 20120740-20120740.

(24) Nagai, Y.; Unsworth, L. D.; Koutsopoulos, S.; Zhang, S. Slow Release of Molecules in Self-Assembling Peptide Nanofiber Scaffold. J. Controlled Release 2006, 115 (1), $18-25$.

(25) Cherif-Cheikh, R.; Bismuth, F.; Torres, M.-L.; Alloza, R.; Bosch, M. T.; Montes, M.; Fuster, E.; Valles, J.; Cordero, J. A.; Peraire, C.; et al. Autogel: A New Lanreotide Prolonged Release Formulation. Proc Int Symp Control Rel Bio Mat 1998, 25, 798-799.

(26) Low, C. M. R.; Black, J. W.; Broughton, H. B.; Buck, I. M.; Davies, J. M. R.; Dunstone, D. J.; Hull, R. A. D.; Kalindjian, S. B.; McDonald, I. M.; Pether, M. J.; et al. Development of Peptide 3D Structure Mimetics: Rational Design of Novel Peptoid Cholecystokinin Receptor Antagonists. J. Med. Chem. 2000, 43 (19), 3505-3517.

(27) Fink, H.; Rex, A.; Voits, M.; Voigt, J.-P. Major Biological Actions of CCK-a Critical Evaluation of Research Findings. Exp. Brain Res. 1998, 123 (1-2), 77-83.

(28) J. F. Rehfeld; Larsson, L.-I.; Goltermann, N. R.; Schwartz, T. W.; Holst, J. J.; Jensen, S. L.; Morley, J. S. Neural Regulation of Pancreatic Hormone Secretion by 
the C-Terminal Tetrapeptide of CCK. Nature 1980, 284 , 33-38.

(29) Rehfeld, J. F. Immunochemical Studies on Cholecystokinin. II. Distribution and Molecular Heterogeneity in the Central Nervou Ssystem and Small Intestine of Man and Hog. J. Biol. Chem. 1978, 253 (11), 4022-4030.

(30) Rehfeld, J. F.; Hansen, H. F. Characterization of Preprocholecystokini Products in the Porcine Cerebral Cortex Evidence of Different Processing Pathways. J. Biol. Chem. 1986, 261 (13), 5832-5840.

(31) Saito, A.; Sankaran, H.; Goldfine, I. D.; Williams, J. A. Cholecystokinin Receptors in the Brain: Characterization and Distribution. Science 1980, 208 (4448), 1155-1156.

(32) M A Gülpinar, B. C. Y. The Physiology of Learning and Memory: Role of Peptides and Stress. Curr. Protein Pept. Sci. 2005, 5 (6), 457-473.

(33) Larsson, L.-I.; Jens F. Rehfeld. A Peptide Resembling $\mathrm{COOH}-$ Terminal Tetrapeptide Amide of Gastrin from a New Gastrointestinal Endocrine Cell Type. Nature 277, 575-578.

(34) Håkanson, R.; Alumets, J.; Rehfeld, J. F.; Ekelund, M.; Sundler, F. The Life Cycle of the Gastrin Granule. Cell Tissue Res. 1982, 222 (3), 479-491.

(35) Kramer, J. R.; Deming, T. J. Reversible Chemoselective Tagging and Functionalization of Methionine Containing Peptides. Chem. Commun. 2013, 49 (45), 5144.

(36) Kramer, J. R.; Deming, T. J. Preparation of Multifunctional and Multireactive Polypeptide via Methionine Alkylation. Biomacromolecules 2012, 13, 1719-1723.

(37) Boultif, A.; Louër, D. Powder Pattern Indexing with the Dichotomy Method. J Appl Cryst 2004, 37, 724-731.

(38) Serpell, L. C. Alzheimer's Amyloid Fibrils; Structure and Assembly. Biochim. Biophys. Acta BBA 2000, 1502, 1630.

(39) Barth, A.; Zscherp, C. What Vibrations Tell about Proteins. Q. Rev. Biophys. 2002, 35 (4), 369-430.

(40) Krimm, S.; Bandekar, J. Vibrational Spectroscopy and Conformation of Peptides, Polypeptides, and Proteins. Adv. Protein Chem. 1986, 38, 181-364.

(41) Susi, H.; Byler, M. D. Fourier TransformInfrared Study of Proteins with Parallel $\beta$-Chains. Arch. Biochem. Biophys. 1987, 258 (2), 465-469.

(42) Byler, D. M.; Susi, H. Examination of the Secondary Structure of Proteins by Deconvolved FTIR Spectra. Biopolymers 1986, 25 (3), 469-487.

(43) Zandomeneghi, G.; Krebs, M. R. H.; McCammon, M. G.; Fändrich, M. FTIR Reveals Structural Differences between Native $\beta$-Sheet Proteins and Amyloid Fibrils. Protein Sci. 2004, 13 (12), 3314-3321.

(44) Sarroukh, R.; Goormaghtigh, E.; Ruysschaert, J.-M.; Raussens, V. ATR-FTIR: A "rejuvenated" Tool to Investigate Amyloid Proteins. Biochim. Biophys. Acta BBA Biomembr. 2013, 1828 (10), 2328-2338.

(45) Barth, A. The Infrared Absorption of Amino Acid Side Chains. Prog. Biophys. Mol. Biol. 2000, 74 (3), 141-173.

(46) Miyazawa, T.; Blout, E. R. The Infrared Spectra of Polypeptides in Various Conformations: Amide I and II bands1. J. Am. Chem. Soc. 1961, 83 (3), 712-719.

(47) van Grondelle, W.; Lecomte, S.; Lopez-Iglesias, C.; Manero, J.-M.; Cherif-Cheikh, R.; Paternostre, M.; Valéry, C. Lamination and Spherulite-like Compaction of a Hormone's Native Amyloid-like Nanofibrils: Spectroscopic Insights into Key Interactions. Faraday Discuss. 2013.
(48) Takeuchi, H. Raman Structural Markers of Tryptophan and Histidine Side Chains in Proteins. Biopolymers 2003, 72 (5), 305-317.

(49) Miura, T.; Takeuchi, H.; Harada, I. Tryptophan Raman Bands Sensitive to Hydrogen Bonding and Side-Chain Conformation. J. Raman Spectrosc. 1989, 20 (10), 667671.

(50) Vivian, J. T.; Callis, P. R. Mechanisms of Tryptophan Fluorescence Shifts in Proteins. Biophys. J. 2001, 80 (5), 2093-2109.

(51) Lakowicz, J. R. Principles of Fluorescence Spectroscopy, 3rd ed.; Springer: New York, N.Y., 2006.

(52) Antzutkin, O. N.; Balbach, J. J.; Leapman, R. D.; Rizzo, N. W.; Reed, J.; Tycko, R. Multiple Quantum Solid-State NMR Indicates a Parallel, Not Antiparallel, Organization of $\beta$-Sheets in Alzheimer's $\beta$-Amyloid Fibrils. Proc. Natl. Acad. Sci. 2000, 97 (24), 13045-13050.

(53) Balbach, J. J.; Petkova, A. T.; Oyler, N. A.; Antzutkin, O. N.; Gordon, D. J.; Meredith, S. C.; Tycko, R. Supramolecular Structure in Full-Lenght Alzheimer's Fibrils: Evidence for a Parallel $\beta$-Sheet Organization from SolidState Nuclear Magnetic Resonance. Biophys. J. 2002, 83, 1205-1216.

(54) Maurer-Stroh, S.; Debulpaep, M.; Kuemmerer, N.; de la Paz, M. L.; Martins, I. C.; Reumers, J.; Morris, K. L.; Copland, A.; Serpell, L.; Serrano, L.; et al. Exploring the Sequence Determinants of Amyloid Structure Using Position-Specific Scoring Matrices. Nat. Methods 2010, 7 (3), 237-242.

(55) Fernandez-Escamilla, A.-M.; Rousseau, F.; Schymkowitz, J.; Serrano, L. Prediction of Sequence-Dependent and Mutational Effects on the Aggregation of Peptides and Proteins. Nat. Biotechnol. 2004, 22 (10), 1302-1306.

(56) Goldschmidt, L.; Teng, P. K.; Riek, R.; Eisenberg, D. Identifying the Amylome, Proteins Capable of Forming Amyloid-like Fibrils. Proc. Natl. Acad. Sci. 2010, 107 (8), 3487-3492.

(57) Trovato, A.; Chiti, F.; Maritan, A.; Seno, F. Insight into the Structure of Amyloid Fibrils from the Analysis of Globular Proteins. PLoS Comput Biol 2006, 2 (12), e170.

(58) Conchillo-Solé, O.; de Groot, N. S.; Avilés, F. X.; Vendrell, J.; Ventura, S. AGGRESCAN: A Server for the Prediction and Evaluation Of "hot Spots" of Aggregation in Polypeptides. BMC Bioinformatics 2007, 8 (65), 1-17.

(59) Tartaglia, G. G.; Pawar, A. P.; Campioni, S.; Dobson, C. M.; Chiti, F.; Vendruscolo, M. Prediction of Aggregation-Prone Regions in Structured Proteins. J. Mol. Biol. 2008, 380 (2), 425-436.

(60) Oakley, A. E.; Perry, R. H.; Candy, J. M.; Perry, E. K. Electron Microscopic Appearances and Implications of Neuropeptide Fibrillary Forms. Neuropeptides 1981, 2, $1-11$.

(61) Hu, K.-N.; McGlinchey, R. P.; Wickner, R. B.; Tycko, R. Segmental Polymorphism in a Functional Amyloid. Biophys. J. 2011, 101 (9), 2242-2250.

(62) Kurouski, D.; Lauro, W.; Lednev, I. K. Amyloid Fibrils Are "alive": Spontaneous Refolding from One Polymorph to Another. Chem. Commun. 2010, 46 (24), 4249.

(63) Valéry, C.; Artzner, F.; Robert, B.; Gulick, T.; GrabielleMadelmont, C.; Torres, M.-L.; Cherif-Cheikh, R.; Paternostre, M. Self-Association of a Peptide in Solution: From $\beta$-Sheet Filaments to Large Embedded Nanotubes. Biophys. J. 2004, 86, 2484-2501.

(64) Nespovitaya, N.; Gath, J.; Barylyuk, K.; Seuring, C.; Meier, B. H.; Riek, R. Dynamic Assembly and Disas- 
sembly of Functional $\beta$-Endorphin Amyloid Fibrils. $J$. Am. Chem. Soc. 2016, 138 (3), 846-856.

(65) Gobeaux, F.; Fay, N.; Tarabout, C.; Mériadec, C.; Meneau, F.; Ligeti, M.; Buisson, D.-A.; Cintrat, J.-C.; Nguyen, K. M. H.; Perrin, L.; et al. Structural Role of Counterions Adsorbed on Self-Assembled Peptide Nanotubes. J. Am. Chem. Soc. 2012, 134 (1), 723-733.

(66) Do, T. D.; LaPointe, N. E.; Economou, N. J.; Buratto, S. K.; Feinstein, S. C.; Shea, J.-E.; Bowers, M. T. Effects of $\mathrm{pH}$ and Charge State on Peptide Assembly: The YVIFL Model System. J. Phys. Chem. B 2013, 117 (37), 1075910768.

(67) de la Paz, M. L.; Goldie, K.; Zurdo, J.; Lacroix, E.; Dobson, C. M.; Hoenger, A.; Serrano, L. De Novo Designed Peptide-Based Amyloid Fibrils. Proc. Natl. Acad. Sci. 2002, 99 (25), 16052-16057.

(68) Dannies, P. S. Prolactin and Growth Hormone Aggregates in Secretory Granules: The Need to Understand the Structure of the Aggregate. Endocr. Rev. 2012, 33 (2), 254-270.

(69) Gopalswamy, M.; Kumar, A.; Adler, J.; Baumann, M.; Henze, M.; Kumar, S. T.; Fändrich, M.; Scheidt, H. A.; Huster, D.; Balbach, J. Structural Characterization of Amyloid Fibrils from the Human Parathyroid Hormone. Biochim. Biophys. Acta BBA - Proteins Proteomics 2015, 1854 (4), 249-257.

(70) Grondelle, W. van; Iglesias, C. L.; Coll, E.; Artzner, F.; Paternostre, M.; Lacombe, F.; Cardus, M.; Martinez, G.; Montes, M.; Cherif-Cheikh, R.; et al. Spontaneous Fibrillation of the Native Neuropeptide Hormone Somatostatin-14. J. Struct. Biol. 2007, 160 (2), 211-223.

(71) Strand, F. L. Neuropeptides: Regulators of Physiological Processes; MIT Press, 1999.
(72) Koulitscher, D.; Moroder, L.; Deschodt-Lanckman, M Degradation of Cholecytokinin Octopeptide, Related Fragments and Analogs by Human and Rat Plasma in Vitro. Regul. Pept. 1982, 4, 127-139.

(73) Dodson, G.; Steiner, D. The Role of Assembly in Insulin's Biosynthesis. Curr. Opin. Struct. Biol. 1998, 8, 189194.

(74) Lemaire, K.; Ravier, M. A.; Schraenen, A.; Creemers, J. W.; Van de Plas, R.; Granvik, M.; Van Lommel, L.; Waelkens, E.; Chimienti, F.; Rutter, G. A.; et al. Insulin Crystallization Depends on Zinc Transporter ZnT8 Expression, but Is Not Required for Normal Glucose Homeostasis in Mice. Proc. Natl. Acad. Sci. 2009, 106 (35), 14872-14877.

(75) Kwon, J.-H.; Lee, B.-H.; Lee, J.-J.; Kim, C.-W. Insulin Microcrystal Suspension as a Long-Acting Formulation for Pulmonary Delivery. Eur. J. Pharm. Sci. 2004, 22 (23), 107-116.

(76) Ellis, R. J. Macromolecular Crowding: Obvious but Underappreciated. Trends Biochem. Sci. 2001, 26 (10), 597-604.

(77) Minton, A. P. Implications of Macromolecular Crowding for Protein Assembly. Curr. Opin. Struct. Biol. 2000, 10 (1), 34-39.

(78) von Zastrow, M.; Castle, J. D. Protein Sorting among Two Distinct Export Pathways Occurs from the Content of Maturing Exocrine Storage Granules. J. Cell Biol. 1987, 105 (6), 2675-2684.

(79) Arvan, P.; Castle, D. Sorting and Storage during Secretory Granule Biogenesis: Looking Backward and Looking Forward. Biochem. J. 1998, 332 (3), 593-610. 


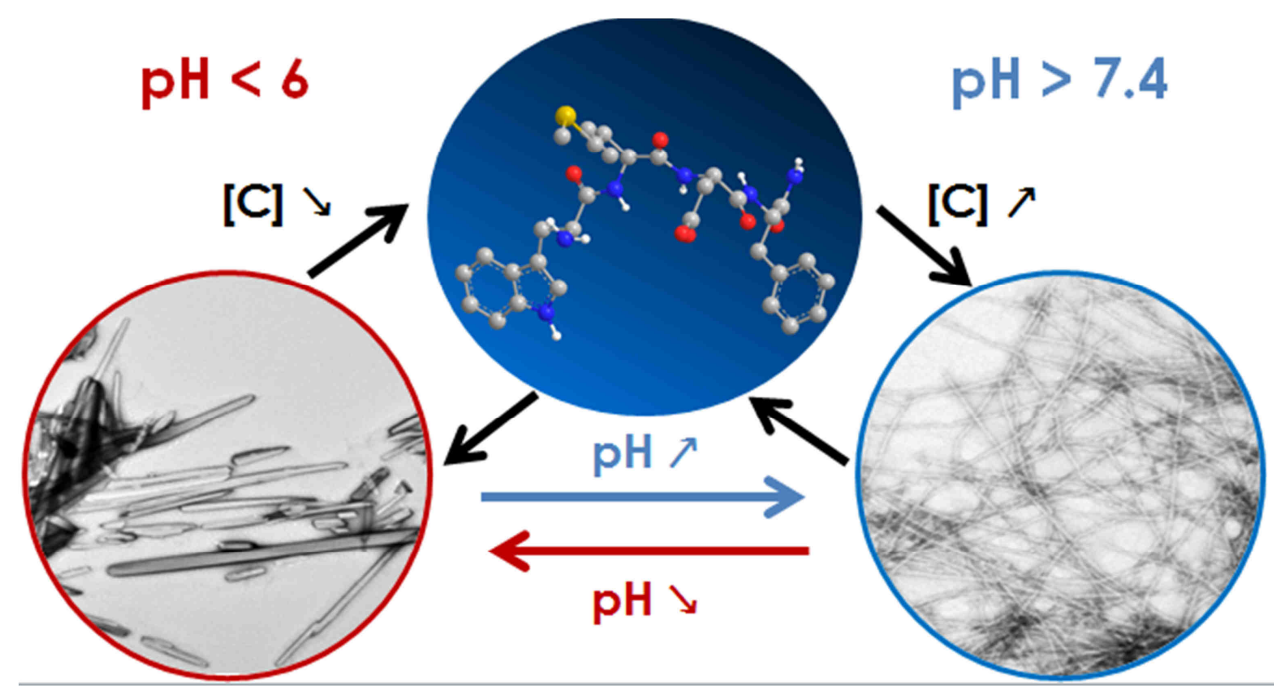

